\title{
Living alone, receiving help, helplessness, and inactivity are strongly related to risk of undernutrition among older home-dwelling people
}

\author{
This article was published in the following Dove Press journal: \\ International Journal of General Medicine \\ 5 March 2012 \\ Number of times this article has been viewed
}

\section{Solveig T Tomstad' \\ Ulrika Söderhamn ${ }^{2}$ \\ Geir Arild Espnes ${ }^{3}$ \\ Olle Söderhamn ${ }^{2}$ \\ 'Department of Social Work and Health Science, Faculty of Sciences and Technology Management, NTNU, Trondheim, Norway and Centre for Caring Research - Southern Norway, Faculty of Health and Sport Sciences, University of Agder, Grimstad, Norway; ${ }^{2}$ Centre for Caring Research - Southern Norway, Faculty of Health and Sport Sciences, University of Agder, Grimstad, Norway; ${ }^{3}$ Research Centre for Health Promotion and Resources HiST-NTNU, Department of Social Work and Health Science, Faculty of Social Sciences and Technology Management, NTNU, Trondheim, Norway}

Correspondence: Solveig T Tomstad Centre for Caring Research - Southern Norway, Faculty of Health and Sport Sciences, University of Agder, PO Box 509, NO-4898 Grimstad, Norway

Tel +4737233762

Email solveig.t.tomstad@uia.no
Background: Being at risk of undernutrition is a global problem among older people. Undernutrition can be considered inadequate nutritional status, characterized by insufficient food intake and weight loss. There is a lack of Norwegian studies focusing on being at risk of undernutrition and self-care ability, sense of coherence, and health-related issues among older home-dwelling people.

Aim: To describe the prevalence of being at risk of undernutrition among a group of older home-dwelling individuals in Norway, and to relate the results to reported self-care ability, sense of coherence, perceived health and other health-related issues.

Methods: A cross-sectional design was applied. A questionnaire with instruments for nutritional screening, self-care ability, and sense of coherence, and health-related questions was sent to a randomized sample of 450 persons (aged 65+ years) in southern Norway. The study group included 158 (35.1\%) participants. Data were analysed using statistical methods.

Results: The results showed that $19 \%$ of the participants were at medium risk of undernutrition and $1.3 \%$ at high risk. Due to the low response rate it can be expected that the nonparticipants can be at risk of undernutrition. The nutritional at-risk group had lower self-care ability and weaker sense of coherence. Living alone, receiving help regularly to manage daily life, not being active and perceived helplessness emerged as predictors for being at risk of undernutrition. The results indicate difficulties in identifying people at nutritional risk and supporting self-care activities to maintain a good nutritional status.

Conclusion: Health care professionals have to be able to identify older home-dwelling people at risk of undernutrition, support self-care activities to enable people at risk to maintain a sufficient nutritional status, and be aware that older people living alone, who receive help, feel helpless, and are inactive are especially vulnerable.

Keywords: health, nutrition, self-care, sense of coherence

\section{Introduction}

Several studies have shown that groups of older people are at risk of undernutrition, ${ }^{1-5}$ and that undernutrition among older people is a global problem. ${ }^{5}$ Older people are a growing group in the world ${ }^{6}$ and this challenge is of serious interest in Scandinavia. Most older people in Norway live at home and many of them in single households. These facts indicate that adequate nutrition may be an essential and critical factor to older people's self-care in order to maintain health and well-being in their daily living. 8 
It has previously been shown that nutritional problems among older home-dwelling people are multifactorial. ${ }^{3,9,10}$ A study among older geriatric rehabilitation patients ${ }^{2}$ showed that people who were found to be at risk of undernutrition reported lower self-care ability and weaker sense of coherence. Studies have also shown associations between being at risk of undernutrition and impaired perceived health among older community-living people. , $^{3,10,11}$

"Undernutrition" has been described as a nutritional status that is not adequate, characterized by insufficient food intake and weight loss. ${ }^{12}$ The risk of undernutrition among older people is a complex and multifaceted problem that is important for physicians, nurses, and other health care professionals to understand. There is a lack of studies on being at risk of undernutrition in older home-dwelling people in Norway and its possible associations with selfcare ability, sense of coherence, perceived health, and other health-related issues.

\section{Background}

Self-care can be described as the practice of activities that people initiate and do on their own behalf to maintain health and well-being. ${ }^{8}$ This influences older people's daily life ${ }^{13}$ and higher self-care ability supports personal health in later life. A strong relationship between lower self-care ability and being at risk of undernutrition has also been shown., ${ }^{2,14}$ A significant association between unintended weight loss and impaired function regarding activities of daily living has been reported among older people living at home. ${ }^{9}$

Based on Pörn's theory of health and adaptedness, ${ }^{15}$ Söderhamn et al developed the Self-care Ability Scale for the Elderly (SASE), ${ }^{16}$ which measures perceived self-care ability. Self-care ability can be defined as the capacity to care for oneself. It may be assessed as the potential for self-care activities, and is, therefore, a necessary condition for such activities. ${ }^{17}$ Söderhamn ${ }^{17}$ also points out that a person's internal recourses for performance of actions may be sufficient, but there also has to be a practical possibility for performing these actions. Self-care ability may be related to several factors according to actual circumstances and includes natural and cultural environments and normative factors. It is also influenced by society's goals and profile. ${ }^{17}$

"Sense of coherence" (SOC) is defined by Antonovsky ${ }^{18,19}$ as a general orientation to life that consists of three components: comprehensibility, manageability and meaningfulness. SOC was developed in order to understand how good health can be experienced in spite of stressful conditions. "Comprehensibility" refers to a person's ability to process and understand both internal and external stimuli as ordered, consistent, and structured, rather than random, chaotic, and inexplicable. "Manageability" refers to the extent to which one is able to dispose adequate resources to meet the demands posed by stimuli that confront one. "Meaningfulness" refers to the extent to which one feels that life is worth investing energy and engagement in, and to consider problems as challenges rather than burdens. ${ }^{18,19}$ The SOC scale was developed to measure the presence of SOC..$^{18}$

Ericsson and Lindström ${ }^{20}$ have shown in a systematic review of empirical studies with SOC that SOC seems to be a resource that promotes health and develops a positive subjective state of health. Schneider et $\mathrm{al}^{21}$ reported that SOC has significant influences on evaluations of perceived health and subjective well-being among older people, and that functional impairment has a slight negative influence on SOC. In a Norwegian study with older nursing home residents, a positive association between SOC and health-related quality of life was reported. ${ }^{22}$

Lindmark et $\mathrm{a}^{23}$ found, in a study that included different adult age groups, that a stronger SOC was associated with health-promoting food choices. Lower SOC scores were associated with a less favourable food pattern. Others have reported that older patients at risk of undernutrition had a weaker SOC. ${ }^{2}$

Sufficient intakes of food and fluid are described in the nursing literature as some of the universal self-care needs that are to be met to enable people to live on their own. ${ }^{8}$ Previous studies among home-dwelling older people have shown that being at risk of undernutrition is associated with perceived ill health ${ }^{3,10,11}$ and other health-related factors, such as receiving help, ${ }^{3}$ perceived helplessness, and not being active. ${ }^{24}$ Nutrition also includes cultural and social aspects, and meals are considered to symbolize care, friendship, love, security and concern. ${ }^{25-28}$ A study among older home-dwelling people ${ }^{3}$ revealed that being at risk of undernutrition was also associated with living alone. Gustafsson and Sidenvall ${ }^{29}$ reported that for older women who had lost their partners, the meaning of cooking and eating was lost and they were at risk of poor nutritional intake.

Studies have shown that undernutrition among older people in developed countries is common and may cause many negative health consequences. ${ }^{5,30}$ To be old and at risk of undernutrition represents complex aspects that include both physiological and nonphysiological factors, ${ }^{5}$ and, therefore, it may be a challenge to support a sufficient food intake and prevent undernutrition in that group of older people. To use a screening instrument can be a help 
for health care professionals in being aware of older people being at nutritional risk. The nutritional screening instrument the Nutritional Form For the Elderly (NUFFE) $)^{31-33}$ was developed for screening older people and it deals with risk factors for older people. Possible associations between being at risk of undernutrition and self-care ability, sense of coherence, and perceived health together with other heath-related and possibly associated factors are important to examine among older home-dwelling people. We have not found this perspective especially focused in previous studies among older home-dwelling people in Norway. This knowledge may be of significance for physicians, nurses and other health care professionals in their work of supporting and enhancing health and well-being among older home-dwelling people.

\section{Aim}

The aim of this study was to describe the prevalence of being at risk of undernutrition among a group of older homedwelling individuals in Norway, and to relate the results to reported self-care ability, sense of coherence, perceived health, and other health-related issues.

\section{Methods}

\section{Design and sample}

This study has a cross-sectional design. A questionnaire was mailed to a randomized sample obtained from the Norwegian Tax Administration in southern Norway (ref 2009/78628) of 450 persons, who were $65+$ years of age in the year in which the study was undertaken, from two counties in southern Norway. The sample consisted of 270 women $(60 \%)$ and 180 men (40\%). After two months, a reminder was sent to those who had not responded $(n=316)$. The final study group included 158 participants $(35.1 \%)$.

\section{Data collection}

Data were collected in 2009 using a self-reported, mailed questionnaire that included the Norwegian versions of the instruments SASE, ${ }^{16}$ the 29-item SOC scale, ${ }^{19}$ and NUFFE. ${ }^{31-33}$ In addition to the instruments the questionnaire included one question about perceived health and several other health-related questions, such as receiving help regularly to manage daily life, receiving help from family or others, receiving home nursing, receiving home help, perceived helplessness, perceiving life as meaningful, and being active. These questions were formulated to elicit "yes" or "no" responses. Background variables such as age, sex, civil status, and type of residence were also included.
The SASE was developed in Sweden and has proved to be a valid and reliable instrument. ${ }^{16,34}$ In accordance with the procedures recommended by Streiner and Norman, ${ }^{35}$ the SASE has been translated from Swedish into Norwegian. The SASE is designed as a summated ordinal, five-point Likert scale. It consists of 17 items that reflect aspects of special concern for older individuals and emphasizes activities of daily living, well-being, mastery, volition, determination, loneliness, and dressing. ${ }^{16,34}$ In accordance with the notion that perceived self-care ability is considered as an attitude with cognitive, affective and behavioural components, SASE has the format of an attitude scale. ${ }^{17}$ The scale has five response categories for each item, which range from 1 ("totally disagree") to 5 ("totally agree"). Four items have to be reversed in the summation of scores because they are negatively stated. The maximal score of the scale is 85 . Lower and higher scores indicate lower and higher perceived selfcare ability, respectively, ${ }^{16}$ and cutoff points were set to $<69$ for lower scores and $\geq 69$ for higher scores. ${ }^{34}$ Consistent with other studies, ${ }^{34,36}$ a neutral score of 3 for missing values was given in this study.

The SOC scale was developed in Israel by Antonovsky. ${ }^{19}$ The scale was designed to consist of the constructs comprehensibility (eleven items), manageability (ten items), and meaningfulness (eight items) with the purpose of registering a fundamental attitude in the sense of a dispositional orientation. The intention was not to measure the three components separately, but to use the SOC scale as a measurement of a whole, described as an orientation to life. ${ }^{19}$ The SOC scale has been translated into a great number of languages, ${ }^{20,37}$ and it has been used in Norwegian studies in different forms. ${ }^{22,38,39}$ In this study, the 29-item version was used. Each item is a semantic differential scale with two anchoring phrases at the ordinal level and ranging from one to seven. Thirteen items are negatively expressed and have to be reversed before summation. The total score ranges from 29 to 203. A higher score indicates a stronger SOC. ${ }^{19}$ A neutral score of four was given for missing values.

The NUFFE was developed in Sweden and designed to identify older individuals being at risk of undernutrition. The instrument has been found to have sufficient psychometric properties both in Swedish studies ${ }^{31,32}$ and in one Norwegian study.$^{33}$ The NUFFE is a summated ordinal scale and consists of 15 three-point items that emphasize dietary history, dietary assessment and assessment of obtaining food products, company at meals, activity, and number of medications. Each item ranges from 0 to 2, with the most advantageous option giving a score of 0 and the most disadvantageous a 
score of 2. The maximum score of the scale is 30 and higher screening scores indicate higher risk of undernutrition. ${ }^{31,32}$ The original Swedish version and the Norwegian version of the NUFFE are tested regarding reliability and validity. ${ }^{31-33}$ Anthropometrical measurements such as body mass index, ${ }^{31-}$ ${ }^{33}$ mid-arm and calf circumferences, ${ }^{32,33}$ and biochemical analysis such as serum albumin ${ }^{31}$ were used to test criterionrelated validity. In this study, median values were given for the particular items in the study group that had missing values. The cutoff points, $<6$ indicating lower risk of undernutrition, $\geq 6$ indicating medium risk of undernutrition, and $\geq 11$ indicating higher risk of undernutrition, based on a Norwegian testing study ${ }^{33}$ of the NUFFE among older patients, were used. The Norwegian version of the nutritional screening instrument Mini Nutritional Assessment was used as a criterion in the testing procedures to determine the cutoff points. ${ }^{33}$

\section{Data analyses}

Descriptive statistics were performed to present the study group and the nutritional screening results. Interval and ordinal data were described with mean (M) values and standard deviations (SD). Nominal data were presented with numbers (n) and percentages (\%).

To analyze differences in age, $t$-test for independent samples (two-tailed probability) was used. Differences in sex were analyzed with Chi-square test (two-tailed probability) regarding the groups of participants and nonparticipants.

To compare the nutritional screening results between age groups, $t$-test for independent samples (twotailed-probability) was undertaken. The Mann-Whitney $U$-test was used to compare the nutritional screening results between groups for SASE and SOC scores. When comparing the nutritional screening results in relation to background variables and health-related variables, the Chi-square test (two-tailed probability) was used, or Fisher's exact test was used when the variables included a group of fewer than five individuals. ${ }^{40}$ The nutritional screening results were dichotomized in NUFFE scores $<6$ (no risk) and NUFFE scores $\geq 6$ (risk).

When multiple comparisons were undertaken for testing differences between groups at no risk and at risk of undernutrition, Bonferroni's correction was used to adjust $P$ values in order to control Type 1 error rate at no more than $5 \%{ }^{40}$

A multiple forward stepwise (conditional) logistic regression analysis was undertaken to examine possible predictors for being at risk of undernutrition. The dependent variable was to be at risk of undernutrition (coded as 1) or not (coded as 0). Independent variables were age, SASE scores, SOC scores, and variables such as living alone (single, widow/er coded as 1 ) or married (coded as 0 ), receiving help regularly to manage daily life (coded as 1 ) or not (coded as 0 ), perceived helplessness (coded as 1) or not (coded as 0 ), being active (coded as 1 ) or not (coded as 0 ), receiving help by family or others (coded as 1) or not (coded as 0 ), receiving home help (coded as 1 ) or not (coded as 0 ), and perceiving life as meaningful (coded as 1 ) or not (coded as 0 ). The independent variables were selected in accordance with the recommendations of Altman; ${ }^{40}$ that is, they reached a $P$ value of $<0.2$ in univariate analyses and the number of variables was suitable in relation to the sample size. Several of the independent variables in the logistic regression analysis were correlated with each other. The range of Spearman's rank order correlation coefficients was between 0.17 and 0.56 , with the highest correlation between SASE scores and SOC scores. Most of the correlations ranged between 0.20 and 0.40 . Stepwise regression was used to avoid misleading findings owing to correlations between the independent variables that were too high. ${ }^{40}$

Statistical significance was set at a $P$ value of $<0.05$. Data were analysed using PASW Statistics 18 (SPSS Inc, Chicago, IL).

\section{Ethical considerations}

The research in this study was designed and performed in accordance with the Declaration of Helsinki ${ }^{41}$ and common principles regarding clinical research, that is, the principles of respect for autonomy, justice, beneficence and nonmaleficence ${ }^{42}$ have been followed. The study was approved by the Regional Committee for Medical Research Ethics in southern Norway (REK Sør-Øst D, registration S-09075d, 2009/933) and by the Norwegian Social Science Data Services (project number 21031).

\section{Results}

\section{Participants and nonparticipants}

The mean age of the participants $(n=158)$ in this study was 73.2 years $(\mathrm{SD}=6.9$ years), ranging from 65 years in the present year to 91 years. Mean age of the men $(n=66)$ was 72.2 years $(\mathrm{SD}=6.3)$ and of the women $(\mathrm{n}=92) 73.8$ years $(\mathrm{SD}=7.2$ years $)$. Mean age of nonparticipants $(\mathrm{n}=292)$ was 76.7 years $(\mathrm{SD}=7.9$ years $)$, significantly higher $(P<0.001)$ than mean age of the participants. There was no difference in the proportion of women and men between participants and nonparticipants. 


\section{Nutritional screening using the NUFFE}

Mean score of the nutritional screening with the NUFFE was $3.7(\mathrm{SD}=2.6)$. The screening showed that $126(79.7 \%)$ participants were at low risk of undernutrition identified with a score $<6$. There were 30 participants $(19 \%)$ at medium risk identified with a score $\geq 6$, and two $(1.3 \%)$ at high risk of undernutrition identified with a score $\geq 11$.

\section{Nutritional screening results related to self-care ability and sense of coherence}

Mean SASE scores and mean SOC scores for the group being at risk of undernutrition and the group at no risk are displayed in Table 1.

\section{Nutritional screening results related to background and health-related variables}

The variables sex, type of residence, and perceived health did not show differences between the group at risk of undernutrition and the group at no risk. When the nutritional screening results were related to age, civil status, receiving help regularly to manage daily life or not, receiving help by family or others or not, receiving home help or not, receiving home nursing or not, being active or not, perceived helplessness or not, and perceiving life as meaningful or not, there were differences between people being at risk of undernutrition and those not at risk (Table 1).

In the nutritional at-risk group, four participants (12.5\%) answered that they received help regularly to manage daily life, and they also reported receiving home nursing and help from family or others. Two of those four participants also reported that they got home help. Another five participants (15.6\%) in the nutritional at-risk group, who reported that they received help regularly to manage daily life, answered that they received help from family or others and also received home help. Three other persons $(9.4 \%)$ reported that they received help regularly to manage daily life and received help from family or others. One person $(3.1 \%)$ received help regularly to manage daily life, but did not answer by whom. Four persons (12.5\%) in the nutritional at-risk group reported that they did not receive help regularly to manage daily life. However, they received help from family or others. Fifteen persons $(46.9 \%)$ in the nutritional at-risk group reported no help.

\section{Predictors for being at risk of undernutrition}

Four predictors emerged in the logistic regression analysis. Living alone, receiving help regularly to manage daily life, and perceived helplessness were found to predict risk of undernutrition. Being active was found to be a protective factor (Table 2).

\section{Discussion}

The aim of this study was to describe the prevalence of being at risk of undernutrition among a group of older homedwelling individuals in Norway and to relate the results to reported self-care ability, sense of coherence, perceived health, and other health-related issues.

The nutritional screening using the NUFFE showed that $19 \%$ of the participants were at medium risk of undernutrition and $1.3 \%$ at high risk. These results were almost the same as the NUFFE screening results in a previous study ${ }^{3}$ among 75-year-old community-living people. Two other studies, using the instrument Mini Nutritional Assessment, reported that $17 \%{ }^{10}$ and $14.5 \%{ }^{11}$ of the older home-living participants were identified to be at risk of undernutrition. Compared with studies among older hospital patients ${ }^{24,43,44}$ and older people living in residential living, ${ }^{1,45}$ the screening results in the present study showed a lower rate of nutritional risk. It has been shown that older home-dwelling people have lower risk of undernutrition than those living in institutions. ${ }^{46}$ The results from a study among home-living older people showed that recent hospital stay is a factor associated with being at risk of undernutrition. ${ }^{10}$ There is therefore a possibility that recently hospitalized older persons represent a more vulnerable group of home-dwelling older persons. It is also reported, however, that older people who were living in a nursing home before their stay in hospital were more likely to be undernourished compared with those who came from their own homes or service flats. ${ }^{4}$ It is important to be aware of this complexity when comparing the nutritional screening results among older home-dwelling persons with groups of older hospital patients and older people living in nursing homes or other sheltered residences.

The present study showed that risk of undernutrition among home-dwelling older persons is associated with advanced age, lower self-care ability and weaker sense of coherence, but it highlights that not being active, perceived helplessness, receiving help regularly to manage daily life, and living alone have strong relationships with nutritional risk. In the following we will discuss these results.

There was a significant difference in age between the group at risk of undernutrition and the group at no risk, but age did not appear as a predictor for being at nutritional risk in the regression analysis. However, it has to be noticed that the response rate is low, and the nonparticipants had higher 
Table I Differences between older persons at no nutritional risk and at nutritional risk and SASE scores, SOC scores, background variables, and health-related issues

\begin{tabular}{|c|c|c|c|}
\hline Variables & $\begin{array}{l}\text { No nutritional risk } \\
\text { NUFFE scores }<6 \\
n=126(79.7 \%)\end{array}$ & $\begin{array}{l}\text { Nutritional risk } \\
\text { NUFFE scores } \geq 6 \\
n=32(20.3 \%)\end{array}$ & $P$ value \\
\hline $\begin{array}{l}\text { Age, mean } \\
\text { (Years, SD) }\end{array}$ & $71.95(6.3)$ & 77.94 (6.9) & $<0.014$ \\
\hline $\begin{array}{l}\text { SASE scores } \\
\text { (Mean, SD) }\end{array}$ & $76.54(7.5)$ & $67.63(11.5)$ & $<0.014$ \\
\hline $\begin{array}{l}\text { SOC scores } \\
\text { (Mean, SD) }\end{array}$ & I54.3 (21.0) & I36.9 (24.7) & $<0.014$ \\
\hline $\begin{array}{l}\text { Sex } \\
\text { Male } \\
\text { Female }\end{array}$ & $\begin{array}{l}55(43.7 \%) \\
7 \text { I (56.3\%) }\end{array}$ & $\begin{array}{l}\text { II (34.4\%) } \\
21 \text { (65.6\%) }\end{array}$ & ns \\
\hline $\begin{array}{l}\text { Civil status } \\
\text { Single } \\
\text { Married } \\
\text { Widow/er } \\
\text { Missing }\end{array}$ & $\begin{array}{l}7(5.6 \%) \\
98(77.8 \%) \\
20(15.9 \%) \\
I(0.8 \%)\end{array}$ & $\begin{array}{l}4(12.5 \%) \\
9(28.1 \%) \\
19(59.4 \%)\end{array}$ & $<0.014$ \\
\hline $\begin{array}{l}\text { Type of residence } \\
\text { Own dwelling } \\
\text { Sheltered living } \\
\text { Missing }\end{array}$ & $\begin{array}{l}122(96.8 \%) \\
2(1.6 \%) \\
2(1.6 \%)\end{array}$ & $\begin{array}{l}30(93.8 \%) \\
2(6.3 \%)\end{array}$ & ns \\
\hline $\begin{array}{l}\text { Good health } \\
\text { Yes } \\
\text { No } \\
\text { Missing }\end{array}$ & $\begin{array}{l}10 \mid(80.2 \%) \\
7(5.6 \%) \\
18(14.3 \%)\end{array}$ & $\begin{array}{l}21(65.6 \%) \\
3(9.4 \%) \\
8(25 \%)\end{array}$ & ns \\
\hline $\begin{array}{l}\text { Receiving help regu } \\
\text { Yes } \\
\text { No } \\
\text { Missing }\end{array}$ & $\begin{array}{l}\text { II }(8.7 \%) \\
\text { II } 4(90.5 \%) \\
\text { I }(0.8 \%)\end{array}$ & $\begin{array}{l}12(37.5 \%) \\
19(59.4 \%) \\
1(3.1 \%)\end{array}$ & $<0.014$ \\
\hline $\begin{array}{l}\text { Being an active per } \\
\text { Yes } \\
\text { No } \\
\text { Missing }\end{array}$ & $\begin{array}{l}\text { II } 15(91.3 \%) \\
8(6.3 \%) \\
3(2.4 \%)\end{array}$ & $\begin{array}{l}20(62.5 \%) \\
\text { II ( }(34.4 \%) \\
\text { I (3.1\%) }\end{array}$ & $<0.014$ \\
\hline $\begin{array}{l}\text { Perceiving life meal } \\
\text { Yes } \\
\text { No } \\
\text { Missing }\end{array}$ & $\begin{array}{l}120(95.2 \%) \\
3(2.4 \%) \\
3(2.4 \%)\end{array}$ & $\begin{array}{l}24(75 \%) \\
6(18.8 \%) \\
2(6.3 \%)\end{array}$ & 0.028 \\
\hline $\begin{array}{l}\text { Receiving home nu } \\
\text { Yes } \\
\text { No } \\
\text { Missing }\end{array}$ & $\begin{array}{l}\text { I }(0.8 \%) \\
123(97.6 \%) \\
2(1.6 \%)\end{array}$ & $\begin{array}{l}4(12.5 \%) \\
27(84.4 \%) \\
I(3.1 \%)\end{array}$ & 0.014 \\
\hline $\begin{array}{l}\text { Perceived helplessr } \\
\text { Yes } \\
\text { No } \\
\text { Missing }\end{array}$ & $\begin{array}{l}7(5.6 \%) \\
117(92.9 \%) \\
2(1.6 \%)\end{array}$ & $\begin{array}{l}10(31.3 \%) \\
20(62.5 \%) \\
2(6.3 \%)\end{array}$ & $<0.014$ \\
\hline $\begin{array}{l}\text { Receiving help fron } \\
\text { Yes } \\
\text { No } \\
\text { Missing }\end{array}$ & $\begin{array}{l}23(18.3 \%) \\
100(79.4 \%) \\
3(2.4 \%)\end{array}$ & $\begin{array}{l}\text { I7 (53.I\%) } \\
\text { I4 (43.8\%) } \\
\text { I ( } 3.1 \%)\end{array}$ & $<0.014$ \\
\hline $\begin{array}{l}\text { Receiving home he } \\
\text { Yes } \\
\text { No } \\
\text { Missing }\end{array}$ & $\begin{array}{l}3(2.4 \%) \\
12 \mathrm{I}(96 \%) \\
2(1.6 \%)\end{array}$ & $\begin{array}{l}7(21.7 \%) \\
24(75 \%) \\
I(3.1 \%)\end{array}$ & 0.014 \\
\hline
\end{tabular}

Note: Bonferroni's correction is used to adjust the $P$ values.

Abbreviations: ns, nonsignificance; NUFFE, Nutritional Form For the Elderly; SASE, Self-care Ability Scale for the Elderly; SOC, Sense of Coherence. 
Table 2 Predictors for being at risk of undernutrition in a population based sample $(n=149)$

\begin{tabular}{|c|c|c|c|c|c|c|c|}
\hline Dependent variable & Predictors & $\mathbf{R}^{2}$ Nagelkerke & B & SE & df & $P$ value & OR (95\% Cl) \\
\hline \multirow{6}{*}{$\begin{array}{l}\text { Risk and no risk } \\
\text { of undernutrition }\end{array}$} & & 0.47 & & & & & \\
\hline & & & & & & & \\
\hline & Living alone & & 2.01 & 0.54 & $\mathrm{I}$ & $<0.001$ & $7.46(2.58-21.53)$ \\
\hline & Receiving help regularly & & 2.23 & 0.70 & I & 0.001 & $9.32(2.39-36.42)$ \\
\hline & Being active & & -1.80 & 0.70 & I & 0.010 & $0.17(0.04-0.65)$ \\
\hline & Perceived helplessness & & 1.93 & 0.80 & 1 & 0.016 & $6.87(1.44-32.78)$ \\
\hline
\end{tabular}

Abbreviations: $\mathrm{B}$, slope; $\mathrm{Cl}$, confidence interval; df, degrees of freedom; OR, odds ratio; $\mathrm{R}^{2}$, determination coefficient; $\mathrm{SE}$, standard error.

mean age than the participants and could be at high nutritional risk. Margetts et $\mathrm{al}^{30}$ reported that risk of undernutrition is increasing with advanced age, and Johansson et $\mathrm{al}^{11}$ reported higher age as a predictor for risk of undernutrition among home-living older persons.

The participants at risk of undernutrition were found to have significant lower self-care ability than the group with no risk. This result is in accordance with Söderhamn et al. ${ }^{2}$ Sørbye et $\mathrm{al}^{9}$ reported a significant association between unintended weight loss and a reduction of activities of daily living among the oldest home-living persons. In the current study, however, lower self-care ability did not appear as a predictor for being at risk of undernutrition. This is not in line with the results in the study by Söderhamn et $\mathrm{al}^{2}$ among older patients, where lower self-care ability was revealed as a predictor. In the present study, other factors turned out to have a stronger relationship with the risk of undernutrition than self-care ability. The results indicate, however, that home-dwelling people at nutritional risk have reduced potential for performing self-care activities in order to maintain a sufficient nutritional status. A study ${ }^{29}$ among older women reported that people with perceived disability in food related work tended to have a lower energy intake that may have consequences for their nutritional status in the long run. However, the reduced power for performing self-care activities to maintain a good nutritional status that the present study indicates, may have several aspects. The practical possibilities of doing such self-care activities may be limited. ${ }^{17}$ The individual's internal resources may also influence ${ }^{17}$ the nutritional self-care.

People at risk of undernutrition had significant weaker SOC than people at no risk. This is consistent with the study by Söderhamn et al. ${ }^{2}$ What the SOC scale really measures has been discussed. ${ }^{47,48}$ From a critical point of view regarding Antonovsky's theory, Bengel et a ${ }^{47}$ claimed that the way a person with a weak SOC is characterized is close to emotional and cognitive symptoms of depression.
This is an interesting perspective, and studies have shown that having more symptoms of depression was a predictor for developing undernutrition among home-dwelling older persons. ${ }^{11,49}$ However, Antonovsky ${ }^{19}$ underlined that persons with a strong SOC are more likely to appraise situations as less tension producing when facing and entering difficult situations and challenges of life. However, Antonovsky ${ }^{19}$ argued that people with weak SOC may believe that they dispose fewer resources to enter challenges in their lives and this impairs their sense of meaningfulness and manageability to face the situations. In our study, older people at nutritional risk perceived life as less meaningful and perceived stronger helplessness than the no risk group. The relationship between being at risk of undernutrition and SOC is interesting, and further qualitative research that describes older people's lived experiences may reveal a deeper understanding.

The present study disclosed no association between being at risk of undernutrition and perceived ill health. This is not in accordance with other studies among older, home-living persons. ${ }^{3,10,11}$ There were, however, eight participants in the nutritional at risk group and 18 in the group with no risk who did not answer the question about perceived health. The question was formulated as a yes or no response. It is possible that this question could be better reported by means of a scale that included more nuances.

Being active was found to be a protective factor for being at nutritional risk. This can also be explained in the way that not being active is a predictor for being at risk for undernutrition. Similar results has been found by Söderhamn et al. ${ }^{24}$ However, our study did not show the participants' interpretations of "being an active person." Being an active person or not may include social, psychological, or physical aspects. Reduced social activity was a predictor for unintended weight loss in a study among older persons living at home, ${ }^{9}$ and Wojszel ${ }^{1}$ reported that undernutrition more often affected persons with limited mobility. According to Ülger et $\mathrm{al}^{4}{ }^{49}$ risk of undernutrition among older people increases 
due to being physically dependent and having chronic illnesses. The result in the present study that not being active is strongly related to risk of undernutrition may indicate increased health problems and perhaps a higher level of illness in the risk group that can influence meal preparation and food intake.

The results showed perceived helplessness as a predictor for being at risk of undernutrition. This may indicate that to take control of their meal situation and nutritional status may be a challenge to older home-dwelling people being at risk of undernutrition. Further on, in accordance with Söderhamn et al, ${ }^{3}$ receiving help regularly to manage daily life, also appeared as a strong predictor in our study. Irrespective of whether the help is formal or not, it is an interesting aspect whether this help supports nutritional self-care activities or not. Some participants in the group who received help regularly also received home nursing. Receiving home nursing was found to be associated with being at risk of undernutrition in the present study. A possible explanation may be that the meal situation was a reason for professional help. However, the association may also indicate that the professional support for the nutritional care was not sufficient. The results also indicate that there are homedwelling older people at risk of undernutrition, who are not identified by professional health care workers as needing support to maintain sufficient nutritional self-care.

Living alone was a strong predictor for being at risk of undernutrition. This is in line with the findings in other studies. ${ }^{2,3}$ This may include several aspects. In one study, ${ }^{50}$ older people living alone were likely to report health problems, decreased physical activity, functional impairment, risk of social isolation, and poor food intake. Gustafsson and Sidenvall ${ }^{29}$ found that older women who had lost their partners, often simplified the entire meal situation and could be at risk of poor nutritional intake, and, furthermore, the meaning of the meals was lost to them. It has also been reported that social isolation among older people can lead to decreased nutritional intake and to depression which may impair their nutritional status. ${ }^{5}$ In the present study there was also an association between perceiving life as not being meaningful and being at risk of undernutrition.

The strong relationships between being old, living alone, receiving help regularly to manage daily life, and risk of undernutrition that were found in the current study need special awareness. Consequently, it is important to identify vulnerable older people who live in single households and to support their nutritional self-care to improve their nutritional status.

\section{Study limitations}

There were a large number of people who did not respond and did not return the questionnaire. The mean age of the participants was lower than of the nonparticipants. The sample, however, included persons in a wide age range, between $65+$ years in the present year and $90+$ years of age. The sex distribution in the participant and nonparticipant group was similar.

There may be several different possible causes explaining the low response rate. The randomized sample of 450 persons was obtained from the tax administration with permission to mail only one reminder if no response. One reminder was probably not sufficient. This can be seen as a limitation. Additional reminders might have given a higher response rate. However, it is known that it is difficult to include older persons in surveys. Sidenvall et a $\mathrm{l}^{51}$ found that those older people who were most active or very ill and disabled did not want to participate. In our study, there is a possibility that the group of nonparticipants had more health problems than the participants and therefore was not able to answer the questionnaire. Health problems increase with age and there is a large number of chronic diseases among older people. ${ }^{52}$ Fatigue is also common in later life $\mathrm{e}^{53}$ and depression is reported to be a common condition that impairs health among older people. ${ }^{54} \mathrm{~A}$ high rate of dementia has also been shown, especially among the oldest old. ${ }^{55}$ To be able to participate in this study by using a mailed questionnaire, a necessary qualification for the participants, was a sufficient cognitive ability. It is also an important aspect to be aware of that eating habits may be difficult and too personal to report. ${ }^{27,51}$

The results of this study should be generalized to a limited degree among older home-dwelling people in the region, especially when the oldest old are considered, and it is also important to consider that the study is based on selfreported data and not by objective measurements of health or nutritional status.

\section{Conclusion}

The results of this study confirm that being at risk of undernutrition is a complex situation for older home-dwelling people. Twenty percent of the participants were identified as being at risk of undernutrition and this group had significantly lower self-care ability and weaker sense of coherence. Moreover, important findings in the study were the strong relationships between being at risk of undernutrition and living alone, receiving help regularly to manage daily life, perceived helplessness, and not being active. 
We recommend further qualitative studies among older home-dwelling persons at risk of undernutrition to get a deeper understanding of their nutritional self-care and how this can be empowered.

\section{Relevance to clinical practice}

Physicians, nurses, and other health care professionals have to be able to identify older home-dwelling persons at risk of undernutrition, support self-care activities to maintain a sufficient nutritional status, and be aware of the fact that older people living alone, receiving help, perceiving helplessness, and being inactive are especially vulnerable to being at risk of undernutrition.

\section{Acknowledgments}

We express our gratitude to the participants of the study, Kirsten Bjørkestøl, University of Agder, for statistical counselling and Nina Falsen Krohn, University of Agder, for English language revision. The study was supported by funds from two county councils, West Agder and East Agder, in southern Norway.

\section{Disclosure}

The authors declare no conflicts of interest in this work.

\section{References}

1. Wojszel ZB. Determinants of nutritional status of older people in longterm care settings on the example of the nursing home in Białystok. $A d v$ Med Sci. 2006;51:168-173.

2. Söderhamn U, Bachrach-Lindström M, Ek A-C. Self-care ability and sense of coherence in older nutritional at-risk patients. Eur J Clin Nutr. 2008;62(1):96-103.

3. Söderhamn U, Christensson L, Idvall E, Johansson AK, BachrachLindström M. Factors associated with nutritional risk in 75-yearold community living people. Int J Older People Nurs. 2012;7(1): 3-10.

4. Vanderwee K, Clays E, Bocquaert I, et al. Malnutrition and nutritional care practices in hospital wards for older people. J Adv Nurs. 2010;6794:736-746.

5. Visvanathan R. Under-nutrition in older people: a serious and growing global problem! J Postgrad Med. 2003;49(4):352-360.

6. World Health Organization. Ageing And Life Course [webpage on the Internet]. Geneva: WHO; 2012. Available from: http://www.who.int/ ageing/en/. Accessed November 1, 2011.

7. Daatland SO, Herolfsen K. Familien $i$ andre halvdelen av livet. [The family in later part of life] In: Slagvold B, Daatland SO, editors. Eldre Ar, Lokale Variasjoner. Resultater fra Den Norske Studien av Livsløp og Generasjon (NORLAG) - runde 1 [Older age, local variations. Results from The Norwegian Study of Life Course and Generation (NORLAG), Part 1]. NOVA Rapport 15/06. Oslo: Norsk Institutt for Forskning om Oppvekst, Velferd og Aldring; 2006:137-160. Norwegian.

8. Orem DE. Nursing: Concepts of Practice. 6th ed. St Louis, MO: Mosby Inc; 2001.

9. Sørbye LW, Schroll M, Finne Soveri H, et al. Unintended weight loss in the elderly living at home: the aged in Home Care Project (AdHOC). $J$ Nutr Health Aging. 2008;12(1):10-16.
10. Johansson L, Sidenvall B, Malmberg B, Christensson L. Who will become malnourished? A prospective study of factors associated with malnutrition in older persons living at home. $J$ Nutr Health Aging. 2009;13(10):855-861.

11. Johansson Y, Bachrach-Lindström M, Carstensen J, Ek AC. Malnutrition in a home-living population: prevalence, incidence and risk factors. A prospective study. J Clin Nurs. 2009;18(9):1354-1364.

12. Chen CC, Schilling LS, Lyder CH. A concept analysis in the elderly. J Adv Nurs. 2001;36(1):131-142.

13. Cohen-Mansfield J, Jensen B. Adequacy of spouses as informants regarding older persons' self-care practices and their perceived importance. Fam Syst Health. 2007;25:53-67.

14. Dale B, Söderhamn U, Söderhamn O. Self-care ability among homedwelling older people in rural areas in southern Norway. Scand J Caring Sci. 2012;26;113-122.

15. Pörn I. Health and adaptedness. Theor Med. 1993;14(4):295-303.

16. Söderhamn O, Ek A-C, Pörn I. The self-care ability scale for the elderly. Scand J Occup Ther. 1996;3:69-78.

17. Söderhamn O. Potential for Self-care. Assessing and Describing Selfcare Ability among Elderly People. Dissertation. Department of Medicine and Care, Division of Nursing Science, Faculty of Health Sciences, Linköping University. Linköping: Linköping University; 1998.

18. Antonovsky A. Health, Stress and Coping. London: Jossey-Bass Inc; 1982.

19. Antonovsky A. Unraveling the Mystery of Health. How People Manage Stress and Stay Well. 1st ed. San Francisco: Jossey-Bass Inc; 1987.

20. Eriksson M, Lindström B. Antonovsky's sense of coherence scale and the relation with health: a systematic review. J Epidemiol Community Health. 2006;60(5):376-381.

21. Schneider G, Driesh G, Kruse A, Nehen HG, Heuft G. Old and ill and still feeling well? Determinants of subjective well-being in $\geq 60$ year olds: the role of the sense of coherence. Am J Geriatr Psychiatry. 2006;14(10):850-859.

22. Drageset J, Nygaard HA, Eide GE, Bondevik M, Nortvedt MW, Natvig GK. Sense of coherence as a resource in relation to healthrelated quality of life among mentally intact nursing home residents a questionnaire study. Health Qual Life Outcomes. 2008;6:85.

23. Lindmark U, Stegmayr B, Nilsson B, Lindahl B, Johansson I. Food selection associated with sense of coherence in adults. Nutr J. 2005;4:9.

24. Söderhamn U, Bachrach-Lindström M, Ek AC. Nutritional screening and perceived health in a group of geriatric rehabilitation patients. J Clin Nurs. 2007;16(11):1997-2006.

25. Kayser-Jones J. Malnutrition, dehydration, and starvation in the midst of plenty: the political impact of qualitative inquiry. Qual Health Res. 2002;12(10):1391-1405.

26. Sydner YM, Fjellström C. Food provision and the meal situation in elderly care - outcomes in different social contexts. J Hum Nutr Diet. 2005;18(1):45-52

27. Fjellström C. Mealtime and meal patterns from a cultural perspective. Scandinavian J Nutr. 2004;48:161-164.

28. Persenius MW. Nutritional Nursing Care. Nurses'Interactions with the Patient, the Team and Organization. Dissertation. Faculty of Social and Life Sciences, Nursing Science, Karlstad University Studies. Karlstad: Karlstad University; 2008:41.

29. Gustafsson K, Sidenvall B. Food-related health perceptions and food habits among older women. J Adv Nurs. 2002;39(2):164-173.

30. Margetts BM, Thompson RL, Elia M, Jackson AA. Prevalence of risk of undernutrition is associated with poor health status in older people in the UK. Eur J Clin Nutr. 2003;57(1):69-74.

31. Söderhamn U, Söderhamn O. Developing and testing the nutritional form for the elderly. Int $J$ Nurs Pract. 2001;7(5): 336-341.

32. Söderhamn U, Söderhamn O. Reliability and validity of the nutritional form for the elderly (NUFFE). J Adv Nurs. 2002;37(1):28-34. 
33. Söderhamn U, Flateland S, Jessen L, Söderhamn O. Norwegian version of the nutritional form for the elderly: sufficient psychometric properties for performing institutional screening of elderly patients. Nutr Res. 2009;29(11):761-767.

34. Söderhamn O, Lindencrona C, Ek A. Validity of two self-care instruments for the elderly. Scand J Occup Ther. 1996;3:172-179.

35. Streiner DL, Norman GR. Health Measurement Scales. A Practical Guide to their Development and Use. 4th ed. New York, NY: Oxford University Press; 2008.

36. Söderhamn O, Lindencrona C, Ek A. Ability for self-care among home dwelling elderly people in a health district in Sweden. Int J Nurs Stud. 2000;37(4):361-368.

37. Antonovsky A. The structure and properties of the sense of coherence scale. Soc Sci Med. 1993;36(6):725-733.

38. Grøholt EK, Stigum H, Nordhagen R, Köhler L. Is parental sense of coherence associated with child health? Eur J Public Health. 2003;13(3):195-201.

39. Langeland E, Wahl AK, Kristoffersen K, Hanestad BR. Promoting coping: salutogenesis among people with mental health problems. Issues Ment Health Nurs. 2007;28(3):275-295.

40. Altman DG. Practical Statistics for Medical Research. London: Chapman and Hall; 1991.

41. World Medical Association. Declaration of Helsinki. Ethical Principles for Medical Research Involving Human Subjects. Seoul: WMA; 2008. Available from: http://www.wma.net/en/30publications/10policies/ b3/17c.pdf. Accessed November 1, 2011.

42. Beachamp TL, Childress JF. Principles of Biomedical Ethics. 6th ed. Oxford: Oxford University Press; 2009.

43. de Oliveira MR, Leandro-Merhi VA. Food intake and nutritional status of hospitalised older people. Int J Older People Nurs. 2011;6(3): 196-200.

44. Söderhamn U, Flateland S, Jessen L, Söderhamn O. Perceived health and risk of undernutriton: a comparison of different nutritional screening results in older patients. J Clin Nurs. 2011;20(15-16):2162-2171.

45. Fossum M, Alexander GL, Ehnfors, Ehrenberg A. Effects of a computerized decision support system on pressure ulcers and malnutrition in nursing homes for the elderly. Int $J$ Med Inform. 2011;80(9):607-617.
46. Elia M, Zellipour L, Stratton RJ. To screen or not to screen for adult malnutrition? Clin Nutr. 2005;24(6):867-884.

47. Bengel J, Strittmatter R, Willmann H. What Keeps People Healthy? The Current State of Discussion and the Relevance of Antonovsky's Salutogenetic Model of Health. Cologne: Federal Centre for Health Education (FCHE); 1999. Available from: http://www.bzga.de/infomaterialien/research-and-practice-of-health-promotion/volume-04-whatkeeps-people-healthy/. Accessed January 15, 2012.

48. Eriksson M. Unravelling the Mystery of Salutogenesis. The Evidence Base of the Salutogenetic Research as Measured by Antonovsky's Sense of Coherence Scale. 2nd ed. Dissertation. Turku: Folkhälsan Research Centre, Health Promotion Research Programme and Folkhälsans Förbund; 2007.

49. Ülger Z, Halil M, Kalan I, et al. Comprehensive assessment of malnutrition risk and related factors in a large group of community-dwelling older adults. Clin Nutr. 2010;29(4):507-511.

50. Kharicha K, Iliffe S, Harari D, Swift C, Gillmann G, Stuck AE. Health risk appraisal in older people 1: are older people living alone an "at-risk" group? Br J Gen Pract. 2007;57(537):271-276.

51. Sidenvall B, Fjellström C, Andersson J, Gustafsson K, Nygren U, Nydahl M. Reasons among older Swedish women of not participating in a food survey. Eur J Clin Nutr. 2002;56(7):561-567.

52. Molarius A, Janson S. Self-rated health, chronic diseases, and symptoms among middle-aged and elderly men and women. J Clin Epidemiol. 2002;55(4):364-370.

53. Jakobsson U. A literature review on fatigue among older people in pain: prevalence and predictors. Int J Older People Nurs. 2006;1(1):11-16.

54. Biderman A, Cwikel J, Fried AV, Galinsky D. Depression and falls among community dwelling elderly people: a search of common risk factors. J Epidemiol Community Health. 2002;56(8):631-636.

55. Poon LW, Jang Y, Reynolds SG, McCarthy E. Profiles of the oldest-old. In: Johnson ML, editor. The Cambridge Handbook of Age and Ageing. Cambridge: Cambridge University Press; 2005:346-353.
International Journal of General Medicine

\section{Publish your work in this journal}

The International Journal of General Medicine is an international, peer-reviewed open-access journal that focuses on general and internal medicine, pathogenesis, epidemiology, diagnosis, monitoring and treatment protocols. The journal is characterized by the rapid reporting of reviews, original research and clinical studies across all disease areas.

\section{Dovepress}

A key focus is the elucidation of disease processes and management protocols resulting in improved outcomes for the patient.The manuscript management system is completely online and includes a very quick and fair peer-review system. Visit http://www.dovepress.com/ testimonials.php to read real quotes from published authors. 